\title{
Correspondence
}

We welcome letters to the Editor concerning articles which have recently been published. Such letters will be subject to the usual stages of selection and editing; where appropriate the authors of the original article will be offered the opportunity to reply.

Letters should normally be under 300 words in length, double-spaced throughout, signed by all authors and fully referenced. The edited version will be returned for approval before publication.

\section{The National Joint Registry for England and Wales}

Sir,

Thank you for drawing your readers' attention to the establishment of the National Joint Registry (NJR) and for highlighting many of the issues which we have to face. ${ }^{1}$

There have been more developments since the writing of your Editorial and we would like to update you and to correct some inaccuracies.

The Steering Committee has 19 members. It now has one additional surgeon representing the British Hip Society and the British Association for Surgery of the Knee. Therefore there are four members representing surgeons, including Jan van de Meulen from the Clinical Effectiveness Unit of the Royal College of Surgeons of England.

The work of the NJR is not controlled by the Department of Health but by the Steering Committee. Individual surgeons will have access to their own data, and follow-up data additional to revision will be obtained.

NJR data will be used to monitor the performance of prostheses and hospitals. The Steering Committee has responsibility for the analyses and hence its membership includes two epidemiologists who are statisticians with special experience in this field. A paper has already been prepared by the Steering Committee concerning the use of data for research purposes.

Initial steps have of necessity focused on the practical problems of consent, gathering of data, verification and ensuring a sound and recurring financial basis to allow the Registry to run autonomously in the future. In its establishment phase the NJR is being funded directly by Government, but from April 1, 2003, it will be selffinancing.

As we move to implementation and attempt to address the many practical problems which surgeons and units will face, it is important to plan and to agree how this information will inform and change practice. The Steering Committee is committed to involving the British Orthopaedic Association, the British Association for Surgery of the Knee, and the British Hip Society in this process and has asked for comments on the initial outline plans for a reporting structure. Without their informed input any analysis is likely to be mechanistic and unlikely to lead to change.

(C)2003 British Editorial Society of Bone and Joint Surgery doi:10.1302/0301-620X.85B4.14321 \$2.00

J Bone Joint Surg [Br] 2003;85-B:618-21.
It is acknowledged that some surgeons have concerns that NJR data will be used to produce surgeon league tables. The Steering Committee can confirm that there is no intention to name individual surgeons at present. The Department of Health has no plans to publish orthopaedic surgeon league tables.

Regional Clinical Co-ordinators have been appointed to provide a focus at a local level and a conduit for communications between the NJR Centre, the Steering Committee and orthopaedic hospitals/units. The general desire of the orthopaedic community to make the NJR work is witnessed by the calibre of those who have taken on these essential roles despite heavy existing commitments.

Minutes of all Steering Committee meetings can be found on the NJR web site at www.njrcentre.org.uk. Other information freely available on the web site includes:

1) The first issue of Joint Approach, the NJR Newsletter

2) The minimum dataset

3) Details of 36 regional clinical co-ordinators and the Strategic Health Authority (England) and NHS regions (Wales) to which they are aligned

4) Presentations, including one given at the Annual Meeting of the British Hip Society on February 27, 2003

5) Full details of the regional training events which are taking place from March 3 to 21, 2003

6) The patient consent form, associated guidance and poster

Comments on existing web material and on future plans are welcome.

While the technical and financial aspects are important, the Registry will be short-lived without the support of the profession and the production of meaningful outcomes which the public (your readers' patients) can understand and support. Considerable pressure will be placed on local management to provide support for the required data input at hospital level.

B. DARLING, Chair, National Joint Registry Steering Committee P. GREGG, FRCS, Vice-Chair, National Joint Registry Steering Committee National Joint Registry

Didcot, UK.

1. Horan F. Editorial. The National Joint Registry for England and Wales. J Bone Joint Surg [Br] 2003; 85-B:1-2.

\section{The natural history and treatment of rupture of the anterior cruciate ligament in children and adolescents}

Sir,

I read with interest the article in the January 2002 issue by Aichroth et $\mathrm{al}^{1}$ entitled 'The natural history and treatment of rupture of the anterior cruciate ligament in children and adolescents'. The authors do not mention the percentage of damage caused by the tunnel on growth plates. Because skeletal development varies, such percentages should be reported. They do not show radiographs of a single 'complete' case although 47 knees were operated on. Growth of the lower limbs is not calculated and there are no data for the Tanner evaluation in relation to the gender. The operation may have been performed in patients in whom the physes were functionally closed. They have stated that "Evidence from experimental animals suggests that more than $7 \%$ of the physis has to be damaged to produce such arrest" with reference to the study of Makela et al. ${ }^{2}$ The latter authors wrote that "the 
destruction of $7 \%$ of the cross-sectional area of the growth plate caused permanent growth disturbances and shortening of the femur".

They state that "an appropriate tunnel involves much less than $7 \%$ of the physis" without giving a reference. In fact there have been no human studies performed to substantiate this statement. They also state that "no child suffered physeal damage or leglength discrepancy". This is the only report so far which states that destruction of a percentage of both physes did not at least show a physiological leg-length discrepancy.

In cases of knee surgery the minimum follow-up period is 12 months from both the biological and mechanical point of view.

The article suggests that "all" children and adolescents can be operated on without any problem, even without preoperative planning, using the four-strand hamstring technique which crosses the growth plates. The literature so far still considers this to be controversial.

No mention has been made of other previous experimental studies. ${ }^{3-5}$ Our work ${ }^{3}$ has been quoted several times by other authors dealing with this subject.

\section{GUZZANTI}

Catholic University of the Sacred Heart

Rome, Italy.

1. Aichroth PM, Patel DV, Zorrilla P. The natural history and treatment of rupture of the anterior cruciate ligament in children and adolescents. J Bone Joint Surg [Br] 2002;84-B:38-41.

2. Mäkelä EA, Vainionpää S, Vihtonen K, Matti M, Rokkanen P. The effect of trauma to the lower femoral epiphyseal plate: an experimental study in rabbits. J Bone Joint Surg [Br] 1988;70-B:187-91.

3. Guzzanti V, Falciglia F, Gigante A, Fabbriciani C. The effect of intraarticular ACL reconstruction on the growth plate of rabbits. J Bone Joint Surg [Br] 1994;76-B:960-3.

4. Janarv PM, Mikstrom B, Hirsch G. The influence of transphyseal drilling and tendon grafting on bone growth: an experimental study in the rabbit. J Pediat Orthop 1998;18:149-54.

5. Stadelmaier DM, Arnoczky SP, Dodds J, Ross H. The effect of drilling and soft tissue grafting across open growth plate: a histologic study. Am J Sports Med 1995;23:431-5.

\section{Author's reply:}

Sir,

We thank Professor Guzzanti for his comments. The percentage damage to the physis by drilling an $8 \mathrm{~mm}$ tunnel is difficult to quantify exactly, but by measurement of the transverse diameters, it is about $2 \%$ on the femoral side and slightly less on the tibial side in the adolescent. It would be approximately $3 \%$ in the pubertal child, at the most.

Figures $2 \mathrm{a}$ and $2 \mathrm{~b}$ were those of a child who had been operated on two years previously. The physes were normal and functioning and the tunnel positions were clearly seen.

On page 39 the Tanner staging was clearly shown. The text confirmed that 24 children were prepubertal and pubertal, and that the remainder were adolescents, all with open physes.

Mäkelä et al $^{1}$ confirmed that destruction of $7 \%$ of the cross-sectional area of the growth plate in rabbits caused permanent growth disturbance. In the paper by Guzzanti et $\mathrm{al}^{2}$ it is stated that in the drilled tibia the damage to the physis was $4 \%$ of the cross-sectional area which produced valgus deformities in 2 of 21 rabbits. One was shortened but not with a full epiphysiodesis.

Attempts to measure the human physis in cross-section have been made as stated in my first paragraph.

Only 16 children had scannograms; the rest had careful clinical assessment of leg lengths and angulation at the knee. No child in the final assessment had a discrepancy of a lower limb outside the physiological norm, and none had an angular deformity of the knee outside the normal physiological bilateral alignment.
Finally, the length of follow-up was variable. The mean was 49 months with a range of 12 to 96 months.

\section{P. AICHROTH, MS, FRCS}

Sunninghill

Ascot, UK.

1. Mäkelä EA, Vainionpää S, Vihtonen K, Matti M, Rokkanen P. The effect of trauma to the lower femoral epiphyseal plate: an experimental study in rabbits. J Bone Joint Surg [Br] 1988;70-B:187-91.

2. Guzzanti V, Falciglia F, Gigante A, Fabbriciani C. The effect of intraarticular ACL reconstruction on the growth plate of rabbits. J Bone Joint Surg [Br] 1994;76-B:960-3.

\section{A randomised comparison of a foot pump and low- molecular-weight heparin in the prevention of deep-vein thrombosis after total knee replacement}

Sir,

We have read with interest the article by Warwick et al ${ }^{1}$ entitled 'A randomised comparison of a foot pump and low-molecular-weight heparin in the prevention of deep-vein thrombosis after total knee replacement' in the April 2002 issue and wish to make the following points.

First, since both patients who died from pulmonary embolism (PE) in the 'foot-pump' group had a record of deep-vein thrombosis (DVT), we question whether patients with a previous DVT should be included in a randomised study on the efficacy of the prevention of thromboembolic disease.

An examination of the statistical findings in terms of DVT between the 'foot-pump' and low-molecular-weight-heparin (LMWH) groups shows that there are no significant differences between them although they are close to significance $(p=0.06)$. The fact that there are no significant differences does not mean that the findings are not clinically relevant. Moreover, the four cases in which there was DVT and the two of patient death from PE give six serious complications all of which are in the LMWH group. The chi-squared test has a a value of 5.57 ( $\mathrm{p}$ value, 0.018), and Fisher's test shows a one-tailed p value of 0.019 and a two-tailed $p$ value of 0.030 which gives statistical significance.

It is not clear from the text whether the patient who died on the 26th postoperative day from PE, and who also had a femoral DVT, was also counted in the DVT group. If this is the case, then there were five, rather than six, cases of serious complications. This would give a chi-squared value of 4.62 ( $\mathrm{p}$ value, 0.031). Fisher's test gives a one-tailed $\mathrm{p}$ value of 0.038 and a two-tailed $\mathrm{p}$ value of 0.060 . Both are statistically significant.

In strictly statistical terms there is no objection to the withdrawal from the study of five patients with clinically diagnosed DVT before the performance of the scheduled venography, and subsequently confirmed by venography or ultrasonography, and a further four with clinically diagnosed PE subsequently confirmed by the relevant complementary tests. Nevertheless, it would be very interesting to know, although statistically tests cannot be applied, how many of them belonged to the 'foot-pump' and 'LMWH' groups, respectively.

We therefore suggest that this study was probably not properly designed, and even if the design proposed by the authors is maintained, the conclusions that "neither method provides superior prophylaxis" cannot be upheld. In our opinion, since there are statistically significant differences, LMWH is better than the use of the foot pump in the prevention of serious thromboembolic complications.

A. M. HIDALGO-OVEJERO

S. GARCIA-MATA

M. MARTINEZ-GRANDE 
Department of Orthopaedics

I. OTERMIN-MAYA

Mecine Service

Ubarmin Clinic and Virgen del Camino Hospital

Pamplona, Spain.

1. Warwick D, Harrison J, Whitehouse S, Mitchelmore A, Thornton M. A randomised comparison of a foot pump and low-molecular-weight heparin in the prevention of deep-vein thrombosis after total knee replacement. J Bone Joint Surg [Br] 2002;84-B:344-50.

\section{Author's reply:}

Sir,

I thank Dr Hidalgo-Ovejero and his colleagues for their interest in our article.

Patients with previous thrombosis are of course a matter of concern. In my view it is appropriate that they were included in the randomised study for two reasons. First, at the time of the study there was no evidence to suggest that the foot pump or low-molecularweight heparin was superior in providing thromboprophylaxis (that is the ethical premise of a randomised study). Therefore, we could expect reasonable protection from thrombosis regardless of the allocation group in the study. Secondly, exclusion of patients from a randomised study will reduce the scope of the investigation and we wished to assess the effect of the foot pump in orthopaedic practice.

Dr Hidalgo-Ovejero is correct that there are no significant differences, but that does not mean the findings are not clinically relevant. An equivalence study always runs a risk of a beta error, hence the importance of trying to make the study as large as practical and using confidence intervals when reporting the results. I would prefer not to include the case of femoral DVT along with the postoperative death because this would count the thrombotic process twice in one patient.

I maintain that our work was properly designed and that our conclusions can be upheld. We aimed to show whether these two methods were more or less equivalent and whether there might be differences in alternative morbidity, such as soft-tissue complications. Thromboprophylaxis is not merely a matter of reducing thromboembolism. If this were so, we could very successfully achieve this by anticoagulation with warfarin to a very high INR The avoidance of soft-tissue complications is equally important. Such balance should always be at the heart of good clinical practice.

D. WARWICK, MD, FRCS, FRCS (Orth)

Southampton General Hospital

Southampton, UK.

\section{Endoscopic versus open carpal tunnel release in bilateral carpal tunnel syndrome}

Sir,

I read with interest the paper in the April 2002 issue by Ferdinand and MacLean ${ }^{1}$ entitled 'Endoscopic versus open carpal tunnel release in bilateral carpal tunnel syndrome'. It is one of the few prospective, randomised blinded trials on the subject, but Table I does not give the patients' hand dominance which could affect the outcome significantly. In addition, the authors commented on return to work as being an outcome measure when $32 \%$ of their patients were not working. Finally, in a large trial Brown, Keyser and Rothenberg ${ }^{2}$ have shown that a two-portal technique is less dangerous and more easily reproducible.

M. WASEEM, FRCS (Trauma \& Orth)

Chadderton,

Oldham, UK
1. Ferdinand RD, MacLean JGB. Endoscopic versus open carpal tunnel release in bilateral carpal tunnel syndrome. J Bone Joint Surg $[\mathrm{Br}]$ 2002;84-B:375-9.

2. Brown MG, Keyser B, Rothenberg ES. Endoscopic carpal tunnel release. J Hand Surg [Am] 1992;17:1009-11.

\section{Author's reply:}

Sir,

We thank Mr Waseem for his interest in our article. Table I did not include the patients' hand dominance since it was noted in the 'Patients and Methods' section. In all cases it was the right hand.

With regard to return to work as an outcome measure, due to the fact that our patients underwent bilateral surgery it was not possible to comment on the relative merits of the different types of surgery in relation to return to full activity and work. This was noted in our discussion.

Finally, with reference to the advantages of the two-portal technique over a single portal as reported by Brown, Keyser and Rothenberg, ${ }^{1}$ the latter technique used the original Agee instrument before its redesign and reintroduction as recorded by them in their paper.

\section{J. G. B. MACLEAN, FRCS (Orth) \\ Perth Royal Infirmary}

Perth, UK.

1. Brown MG, Keyser B, Rothenberg ES. Endoscopic carpal tunnel release. J Hand Surg [Am] 1992;17:1009-11.

\section{Arthroplasty of the hip}

Sir,

I read with interest the paper in the April 2002 issue by White and Dougall ${ }^{1}$ entitled 'Arthroplasty of the hip'. At first sight the conclusions are surprising and are in danger of giving the impression that change of leg length is not important. I feel that the authors would not wish this. Unlike them I regret not being able to produce firm statistics to support my view that lengthening of more than 1 $\mathrm{cm}$ is often noticed by the patient while shortening of up to $2 \mathrm{~cm}$ may be unperceived. This is due to the patient with lengthening having to 'climb' on to the relevant limb with each step. Pain may be associated with lengthening. Gurney et $\mathrm{al}^{2}$ record objective evidence for the disadvantage for $2 \mathrm{~cm}$ of discrepancy.

The authors state that they had examples of lengthening by 35 $\mathrm{mm}$ and in my view this would be negligent, except of course in a complex case. Nowadays, in the absence of some exceptional and usually foreseeable circumstance, leg-length accuracy should be within $1 \mathrm{~cm}$. The time to assure this is during the operation by choosing some fixed point for reference, having previously assessed whether deliberate change in length may be beneficial.

I ask whether any of the patients noticed inequalities of leg length. It is likely that in most patients the relief from pain will have compensated for the inconvenience of leg lengthening and thus be masked by the instrument used to assess satisfaction. I question why the authors chose to use the leg-length ratio in their scattergram of inequality and not, as would be more immediately understandable, a simple illustration as to acquired differences in leg length. It is also important to relate these to any pre-existing measurements of leg length.

\section{R. A. ELSON, FRCS \\ Northern General Hospital \\ Sheffield, UK.}

1. White TD, Dougall TW. Arthroplasty of the hip: leg length is not important. J Bone Joint Surg [Br] 2002;84-B:335-8 
2. Gurney B, Mermier C, Robergs R, Gibson A, Rivero D. Effects of limb-length discrepancy on gait economy and lower-extremity muscle activity in older adults. J Bone Joint Surg [Am] 2001;83-A:907-15.

\section{Authors' reply:}

\section{Sir,}

We thank Mr Elson for his interest in our paper. We agree that a postoperative limb-length inequality of less than $1 \mathrm{~cm}$ is desirable in most routine hip arthroplasties. In our series of 200 patients although 41 had lengthening of more than $1 \mathrm{~cm}$, only in one was lengthening of an estimated $35 \mathrm{~mm}$ and in three it was between 21 and $30 \mathrm{~mm}$.

We found no statistical correlation between the degree of lengthening, satisfaction and function among our patients. We acknowledge and share Mr Elson's interest in the outliers with discrepancies of over $2 \mathrm{~cm}$. Although there were only four such outliers, we do not believe that poorer outcomes for theses patients have been concealed by the data for the remainder of the group: the scatter plot presented in our paper shows that the results for these outliers are entirely representative of the group as a whole, and no trend to poorer outcome is evident. We stand by our conclusion. Although the article by Gurney et $\mathrm{al}^{1}$ is of much interest, by the authors' own admission, this shows the effects of lengthening in the acute situation in experimental subjects, who were, by definition, aware of an imposed limb-length discrepancy. It does not infer that later adaptations to the situation cannot occur.
Our study was planned to avoid the bias which would have been introduced if patients had been specifically told that they had been lengthened or shortened by operation. We acknowledge that a small degree of dissatisfaction with a leg-length inequality may be masked by overwhelming satisfaction with the relief from pain afforded by arthroplasty, but we feel that any substantial dissatisfaction with leg length would necessarily colour the patients' impressions of their outcome as a whole and this would be reflected in our scale accordingly. If lengthening causes pain this would be confirmed in the pain component of the Harris hip score which was independently analysed and no causal relationship was identified.

We used a length ratio because it minimises the errors which are incurred in calculating a magnification. It is also a useful method of analysing whether patients of short stature are more affected by lengthening than those with longer limbs.

We agree that looking at overall leg length would be an interesting addition to a study of this nature. However, as clinical measurement is notoriously unreliable, scientific rigour would require the use of scanograms. This has implications in regard to additional costs and patient irradiation and is thus beyond the scope of our project.

\section{T. O. WHITE, AFRCS}

T. W. DOUGALL, FRCS Orth

Queen Margaret Hospital

Dunfermline, UK.

1. Gurney B, Mermier C, Robergs R, Gibson A, Rivero D. Effects of limb-length discrepancy on gait economy and lower-extremity muscle activity in older adults. J Bone Joint Surg [Am] 2001;83-A:907-15. 